\title{
El oro azul: entre la apropiación social y su mercantilización
}

\author{
Byron Barillas ${ }^{1}$ y Luis Bonilla ${ }^{2}$
}

1. Egresado Facultad de Derecho, USAC, Guatemala, Bachiller y Licenciado en Sociología, UNA, Costa Rica. Profesor e investigador de la Cátedra de Sociología, Escuela de Ciencias Sociales y Humanidades, UNED, Costa Rica. Actualmente responsable del Programa de Pedagogía en Derechos Humanos del Instituto Interamericano de Derechos Humanos. Responsable de investigación y coordinador adjunto de la Comisión de Derechos Humanos para Centroamérica. Correo electrónico: bbarillas@gmail.com

2. Bachiller y licenciado en Sociología, UNA, Costa Rica. Con estudios en educación ambiental, actualmente realiza tesis doctoral en Estudios Latinoamericanos en la UNA. Profesor e investigador de la Cátedra de Sociología, Escuela de Ciencias Sociales y Humanidades, UNED, Costa Rica. Profesor en la Escuela de Administración de la UNA. Correo electrónico: luvibon9@gmail.com

Recibido: 22 de julio 2013 • Aprobado: 11 de setiembre 2013

RESUMEN

El presente artículo plantea una reflexión teórica sobre lo que denominamos: el carácter social del agua, en cuya expresión se condensa la génesis misma de la evolución humana dado el vínculo vital e histórico de los seres humanos con el preciado líquido. Sin embargo, tal como lo afirmamos en la reflexión propuesta, el nexo del recurso hídrico con lo social, o más bien con necesidades sociales fundamentales, es disuelto históricamente por nuestro alejamiento de las fuentes hídricas naturales de modo que, por razones de acceso al preciado líquido, tal vínculo -fetichizado según algunos autores- se torna indefectiblemente dependiente de intermediaciones tecnológicas y humanas e inversiones económicas que hace más compleja su explicación y, por lo tanto, necesario el uso de referentes y categorías teóricas duras como lo es la teoría marxista del valor.

Palabras clave. Construcción social del agua, fetichismo, valor de uso, valor de cambio, conflicto.

\section{ABSTRACT}

This article poses a theoretical reflection on what we refer to as the social character of water. Water is at the genesis of human evolution itself, given the vital and historical connection between human beings and this valuable liquid. However, as we affirmed in the proposed suggestion, the link between the hydraulic resource and the social (or actually those fundamental social needs) has gotten historically dissolved due to our alienation from natural water sources. So because of reasons related to access to this precious liquid, such link - which has been fetishized, according to some authors- has become unavoidably dependent on technological and human interventions, as well as on economic investments. This makes explaining it more complicated, thus the need to use hard theoretical categories and references such as the Marxist theory of value.

Keywords. Social construction of water; fetishism; use value; exchange value; conflict.

\section{Introducción}

El documento es parte de los productos de una primera etapa de investigación realizada durante más de un año desde la Cátedra de
Sociología de la ECSH-UNED con el nombre original de "Gestión del agua y Acueductos Rurales en Costa Rica" en el cual se planteó como objetivo general analizar el modelo de gestión institucional del agua mediante el cual se crean 
los acueductos rurales con participación comunitaria. Durante el proceso de indagación y reflexión crítica, logramos establecer al menos tres períodos de ruptura y reorientación de la gestión del agua entre la segunda década del Siglo XX y la primera década del Siglo XXI que han implicado importantes cambios de relacionamiento social y conflicto con el Estado y empresas privadas a instancias del recurso hídrico.

En las ciencias sociales solemos hablar de procesos, los cuales se construyen a partir de ciertos imaginarios, sean éstos de orden económico, social, político, cultural e ideológico, que van decantando una cierta forma de establecer los relacionamientos sociales entre los grupos o clases en determinado tiempo y espacio socio-histórico. Dependiendo de cuan desarrollados estén esos imaginarios colectivamente, o sea, de cuánto esos "intereses idealizados" se materialicen en una práctica social, así será la magnitud y la calidad del proceso que se construya en una determinada formación social.

De alguna forma esta idea se puede relacionar, también, con aquel clásico planteamiento marxista en el sentido que "la humanidad se plantea siempre únicamente los objetivos que puede resolver..." (Marx, 1989: 8), lo cual, para los propósitos de ésta reflexión en torno al tema del agua y su carácter social, nos parece que ambos planteamientos son útiles para intentar un ejercicio de comprensión socio-política de esta experiencia concreta que visualizamos, a su vez, como un proceso de construcción social del agua.

No es muy usual en ciencias sociales acuñar una noción del agua como constructo social, aunque siempre hemos sabido que este recurso natural está en el centro de la vida, en los límites de la sobrevivencia humana y de toda especie viviente. Por ser el agua uno de los recursos abióticos esenciales, poco se le percibe y comprende a la vez como uno de los elementos que organizan la vida social y económica, capaz de mover no solo múltiples intereses privados y públicos, sino de generar conflictos de no poca envergadura. Habrá de reconocerse que, quizás por el antropocentrismo dominante, el análisis del agua como construcción social ha sido bastante marginal. .

Por eso, desde un enfoque sociológico, como objeto y herramienta metodológica para el análisis, proponemos el concepto de construcción social del agua, entendiendo por tal, al conjunto de relaciones sociales: de trabajo, gestión, administración, consenso, disenso, conflicto y lucha social que se urden en torno al agua.

Es la anterior, una modesta definición derivada de constataciones empíricas cuyas articulaciones sociales con el agua tienen lugar, tanto en realidades menos complejas como pueden ser comunidades campesinas o los pueblos originarios hasta otras muy complejas; tal es el caso de los nexos con el agua construidos en el marco de las sociedades urbano-capitalistas. En los conglomerados urbanos, la complejidad no es sólo por la cantidad de los actores involucrados, sino por la mezcla de tan variados intereses a conciliar.

En el marco del neoliberalismo y, a la luz de la I etapa de la investigación concluida en el año 2012, curiosamente detectamos que dicha complejidad en los procesos de construcción social del agua están ocurriendo más bien en zonas geográficamente alejadas de las urbes, donde los intereses corporativos son muy claros; a modo de ejemplo, señalamos el caso del acueducto de Sardinal, Guanacaste, donde los estudios de viabilidad e impacto ambiental pagados por intereses privados contaron con el visto bueno del mismo Instituto de Acueductos y Alcantarillados (AyA), y aparece así, lo que hemos dado en llamar una "mediación tramposa" de una institución estatal "mediando" intereses privados; pero existen otros focos de conflicto con sus propias peculiaridades.

En resumen, desde este imaginario sociológico nos avocamos a la tarea de reflexionar sobre un entramado complejo entre ser humano y naturaleza en el contexto costarricense, donde el agua será nuestro hilo conductor yse prevé que buena parte de la disputa por el vital recurso ya tiene sello de mercancía, pero a la que también se le opone otra lógica: la reivindicación del agua como derecho. 


\section{La construcción de un proceso: imaginarios políticos}

En la investigación desarrollada acerca del tema de los Acueductos Rurales con participación social, descubrimos la existencia de un proceso de construcción social que tiene al menos tres etapas, que no profundizamos aquí por razones de espacio (ver informe de investigación etapa I), pero que, en general, sus antecedentes problemáticos surgen en la década de los años veinte del siglo pasado. En términos de imaginario político, se inscribe en el marco del liberalismo decimonónico de tradición europea, inspirado en valores económicos individualistas y centrado en el principio de "dejar hacer y dejar pasar" (Mora, 1992: 19).

De ahí que fuera una corriente que no le interesaba intervenir en la economía, "la distribución de la riqueza" o la vida social y cuando lo tuvo que hacer, como ocurrió en distintos momentos ya desde mediados del siglo XIX hasta la década de los años veinte, fue para coadyuvar con la iniciativa empresarial motivada por "razones económicas utilitarias"3 (Arias, 2004: 295). Una economía que si bien enuncia el principio de "la máxima felicidad para el mayor número" es un "criterio de una psicología humana simplificada" que para Schumpeter (citado en Sunkel y Paz, 1978: 108, 109) se trata de una idea "asociada a la mentalidad de los negocios y a la filosofía de la vida del empresario", el criterio pues, no incluye al común de los mortales, sino al "hombre de negocios".

Por eso, durante los años veinte, cuando el país sigue acuciado por los problemas de salubridad pública y que tiene efectos nocivos tanto en la población en general como en la fuerza de

3. Para Arias (2004), algunos ejemplos, aunque "de poca significación social" fueron: la prohibición de trabajar la noche en los trapiches (Decreto IV del 27 de enero de 1841), para disminuir accidentes de trabajo; Ley No. 6 de 1886 (ley de pensiones para maestros titulados); Ley No. 37 de 1918 (Ley de pensiones para empleados de telégrafo y teléfonos; Ley No. 53 de enero de 1925 (Accidentes de Trabajo), entre otras. Pág. 295. trabajo costarricense, sobre todo de aquella que está siendo utilizada en el enclave bananero de la compañía estadounidense United Fruit Company, aparece en la escena política la presión de entidades como la Fundación Rockefeller que al principio colaboró en la atención de los problemas de salubridad de los trabajadores y luego, el irse del país, presionó por la intervención del Estado para garantizar una fuerza de trabajo más saludable a la transnacional.

En este contexto, destaca el decreto de Estado No. 3 del 21 de julio de 1920, que creó las Juntas Sanitarias Patrióticas, el cual buscaba el apoyo popular en la lucha sanitaria del país (Mora, 1992: 24). Lo relevante de este decreto es que será el detonante para que las primeras comunidades urbanas que lo aplicaron lo asimilaran, pero dándole su propio significado, es decir, comprendieron que dicho decreto solo les daba participación en temas de higienización pero no en los temas sociales y comunales que era una de sus preocupaciones. Es así como desde las primeras juntas creadas, por ejemplo la del Barrio México (1921), se decide cambiarle el nombre por el de Juntas Progresistas.

Este es el origen de un proceso bastante largo llevado a cabo por una organización comunal autónoma con una capacidad de convocatoria muy grande que acumuló fuerza social y lideró varias luchas, dentro de ellas las luchas por el agua durante las décadas de los años 50 y 60 ; esto sin contar las luchas comunales de la primera mitad del siglo XX para dotar de acueductos a muchos barrios capitalinos, llevar alumbrado público, arreglar calles, etc., asimismo, las luchas y huelgas de pago de recibos exageradamente altos contra la empresas de energía eléctrica en los años 40 y 60s.

Tal y como lo señalamos anteriormente, con el principio filosófico del laisser faire laisser passer se advierte lo que sería la esencia del liberalismo, el cual trataba de impedir todo tipo de intervención en los asuntos de la vida económica y social asumiendo así un frío pragmatismo que le beneficiaba como corriente política para consolidarse en el poder. Era una especie de filosofía basada en el cálculo político, de ahí que 
no interviniera prácticamente en nada, y eso significó para el movimiento comunal autónomo que tampoco le impidiera su avance que prácticamente fue incontenible, aunque siempre lo intentó controlar por medio de otros decretos que buscaban deslegitimarlo.

Por tanto, la década de los años veinte y siguientes implica también la construcción social de procesos basados en otros imaginarios políticos que darán su fruto en la década de los cuarenta y más allá. En este punto, confluyen actores con intereses ideológicos diversos que prefiguran el futuro político del país y van desde los partidos de orientación católica que buscan acumular una fuerza social que hiciera frente a la arremetida liberal, como fue el partido reformista de Jorge Volio; el de pensamiento social cristiano del cual devino en la figura del Doctor Calderón Guardia $\mathrm{y}$, por último, el surgimiento del partido comunista a inicios de los años treinta; éste último, actor político determinante en la huelga bananera de 1934 por lo que, como resultado, se inicia formalmente la lucha de clases en Costa Rica. Son pues imaginarios políticos bastante disímiles, pero que influyen en la sociedad de la época hasta definir un nuevo rumbo de país a partir de los años cuarenta.

De esta manera, la construcción de este proceso social brevemente descrito implicó la participación de distintos actores sociales donde se confrontaron ideas políticas de distinto signo ideológico que tiene su punto culminante y de quiebre en la década de los cuarenta. Hay aquí una dialéctica de "contrarios" en todo este proceso en donde los resultados de la revolución del 48 , al producir una nueva carta magna con otra orientación política que será impulsada por las clases emergentes, vendrían a significar la síntesis del proceso. Dialécticamente, ese sumario se constituye históricamente en nuevo punto de partida de otro proceso que va creando sus propias contradicciones con sus momentos de ruptura y de consolidación. Esto ocurre, ya que la sociedad no es "estática" como suponen algunas corrientes sociológicas, sino al contrario, siempre está en “movimiento". (Camacho, 2001: 34).
Por tanto, con el concurso de estos imaginarios políticos desarrollados en la primera mitad del siglo pasado, si bien -como hemos dicho- tiene su punto de quiebre en la década de los cuarenta, constituyen a su vez, el punto de partida que marca la construcción social de los procesos que se desarrollan en su segunda mitad. Particularmente, la lucha social desplegada alrededor del agua no puede ser comprendida a cabalidad si se ignora dicho antecedente; sobre todo porque uno de los actores beligerantes en la construcción de "comunidad" desde los años veinte, las Juntas Progresistas, adquiere en los años 50 y 60 un mayor protagonismo social. Este hecho ha sido analizado en la investigación (etapa I) como elemento clave para concebir en 1965 el Programa de Acueductos Rurales que buscaba, entre otras cosas, disputarle a esta organización la hegemonía política adquirida en las luchas por el agua.

\section{Hacia un marco conceptual-metodológico del recurso hídrico}

En este apartado se propone una delimitación conceptual y metodológica tratando de establecer algunas premisas que posibiliten la comprensión del recurso hídrico dentro de una formación social como la costarricense, ubicada en el marco de un capitalismo periférico de arraigo latinoamericano.

Creemos que esta delimitación metodológica puede ser útil para comprender algunas singularidades que adquiere el tema del recurso hídrico en Costa Rica, pero entendido como algo que no está escindido del resto de la economía costarricense, sino más bien como parte de esta y cada vez más insertada en los circuitos de la economía global. Se la sitúa pues, como una economía sometida a los vaivenes que adquieren las dinámicas de las metrópolis con sus impredecibles tendencias en una época de "crisis sistémica" a la que se enfrenta el capitalismo actual, empero, casi siempre orientadas hacia una permanente "vulnerabilidad" e "inestabilidad" (Vargas, 2008:101).

Cabe resaltar que si algo es característico de las economías periféricas como la nuestra es su marcada persistencia a coexistir una con la 
"otra": la de "la informalidad" que, de acuerdo con Vargas (2013:1), sobrepasa al tercio de los trabajadores y trabajadoras del país; una vertiente económica que se desarrolla, por decirlo de un modo, en los "bordes del sistema", o sea con formas cercanas o reales a la "producción no capitalistas" (Bartra, 2008:121), semi-clandestina, poco apreciada y reconocida oficialmente. Sin embargo, dicha economía es generadora de bienes y servicios que incluyen una amplia dinámica de trabajo creador y de valorización de capital del cual también se sirve el sistema como tal.

No se trata aquí de hacer un análisis económico, sino de esbozar el contexto actual precisando algunas categorías desde las ciencias sociales en su vertiente crítica que den cuenta de las formas y las tendencias que adquieren los nuevos procesos de relaciones sociales en materia de gestión, administración y apropiación del recurso hídrico que ya es orientado -aunque a veces un tanto subrepticiamente- desde una estrategia de mercado.

\section{La extensión del mundo de las mercancías}

En esta línea Bartra (2008: 121) plantea que "el capitalismo necesita, para su existencia y desarrollo, estar rodeado de formas de producción no capitalistas" y que "no hay ninguna razón por la cual los medios de producción y consumo [...] hayan de ser elaborados exclusivamente en producción capitalista" (Bartra cita a Luxemburgo, 1967: 279), lo cual significa que hay "un horizonte de relaciones económicas atípicas según la ortodoxia del capitalismo y sin embargo esenciales para el sistema".

Es decir, no hay por qué suponer que la manufactura o generación de mercancías es un proceso que solamente puede darse en el marco de relaciones sociales de producción típicamente capitalistas, ya que el sistema ha creado las condiciones para que estas otras formas de producción se integren o sean subsumidas a su lógica de acumulación; lo que por otra parte significa una perversión de dicho sistema al ser incapaz de autocrearse a partir de sus propias formulaciones teóricas de la economía burguesa para la producción de mercancías en la relación capital-trabajo. En otras palabras, que supone una relación siempre formal, típica del modo de producción capitalista, de donde se deriva la asignación del valor que adquieren tales mercancías destinadas al intercambio; sin embargo, esto no ocurre en el capitalismo realmente existente.

Estamos ante una especie de capitalismo "deforme" que no soporta las leyes básicas del mercado, las cuales están sostenidas en su propio edificio teórico delineado desde los clásicos de la economía como Smith, Ricardo, entre otros. Una deformación que nos parece es llevada hasta los extremos por la corriente neoliberal que azota el mundo desde las últimas décadas del siglo pasado, sobre todo en las economías de la periferia en las que las formas no capitalistas de producción incluyen la "guerra" contra la naturaleza, lo cual genera un mayor "parasitismo" global en el sistema capitalista que viola cualquier principio de la misma "moral burguesa" también heredada de los clásicos, pero hoy tirada por la borda ante la "depredación acelerada de los recursos naturales (en especial energéticos y renovables)" (Beinstein, 2009: 3).

Se trata pues de "disformidades" que no son simples "supervivencias" del capitalismo sino "creaciones" que no ocurren sólo en la periferia sino, también, en las economías centrales; por lo que Hirch, citado por Bartra (2008:122) argumenta:

El hecho de que las relaciones internacionales del capital se hayan basado desde siempre en una multiplicidad de formas de producción, dominación y explotación, en el curso de la globalización se expresa [...] con mayor nitidez, en los mismos centros capitalistas, cuyas sociedades no sólo se están caracterizando por crecientes diferencias sociales y culturales sino además por la proliferación, entre sus habitantes, de relaciones laborales informales y "periféricas" (Bartra, 2008:122).

Lo planteado por Hirch, es un síntoma inequívoco de hasta donde ha llegado la decadencia de este sistema que ya ni siquiera en los espacios metropolitanos es capaz de desarrollar y sostener relaciones económicas típicamente formales, lo 
que ha dado lugar a una suerte de descomposición acelerada en la relación capital-trabajo al expeler toda la fuerza productiva que no logra integrar al sistema formal. Esta idea, estaría emparentada con la tesis de Bartra $(2008: 148,149)$ cuando califica al capitalismo actual como un sistema vomitivo, es decir, que expulsa hacia fuera lo que no logra asimilar. Asimismo, estamos ante una "polarización del mundo" que recrea un viejo debate, pero ahora replanteado: hoy se trata de "un Tercer mundo en el Primer Mundo y de un Primer Mundo en el Tercer Mundo. Los polos puros se han disuelto" (Hinkelammert, s.f.: 22).

Para nosotros, este tipo de "transpolación" o especie de entramado contradictorio entre ambos mundos, de por sí muy disímiles, nos muestra en perspectiva no solo la degradación del sistema como tal, que no ha sido capaz de llevar el bienestar para todos en sus centros neurálgicos, sino además, de lo engañoso que ha sido el discurso moderno del progreso, pero que todavía se sigue utilizando como concepto fuerte del capitalismo decadente como sistema de regulación social.

Siguiendo a Casanova (2006:1), hay que añadir que en la "guerra" contra la naturaleza, en la que aparece explícita o implícitamente el agua, están incluidos también los más pobres de la tierra, los campesinos, los pueblos originarios, porque son ellos los que más dependen de la naturaleza para sus economías de subsistencia familiarcomunitaria, que aun no siendo una economía "competitiva" también los "alimenta".

Según Vandana Shiva (s.f.), "las guerras del agua" en el mundo periférico están vinculadas a los proyectos hidroeléctricos, la minería y las grandes plantaciones agrícolas, que destruyen ecosistemas hídricos y desplazan campesinos y etnias, de ahí que la autora considere que las guerras con carácter étnico o religiosas desarrolladas en muchas partes en realidad son guerras por el control de recursos naturales como el agua, entre otros.

Por tal motivo, en cada proyecto que los Estado-Nación llaman de "desarrollo", como son las represas hidroeléctricas, los primeros en sufrir el saqueo y despojo de sus tierras son los pueblos originarios y campesinos; Centroamérica es un ejemplo actual. Lo mismo ocurre en la agricultura, la gran empresa capitalista invade y expropia tierras con la complicidad del Estado y la presión de latifundistas, usualmente blancos; un dramático ejemplo es lo que ocurre en algunos países de África en donde millares de campesinos han tenido que migrar de sus tierras ante la irrupción del cultivo de palma que cubre millones de hectáreas destinada a producir "agrocombustibles", la nueva energía que demandan las economías centrales (Francois Houtart: conferencia dictada en la Universidad Nacional, agosto, 2009).

No obstante, como sugiere Bartra (2008: 129), esta acelerada carrera contra la naturaleza constituye al mismo tiempo los límites del capitalismo. Entonces, diríamos que más allá de la naturaleza externa al ser humano, y una vez que la depredación llevada a extremos le impone límites al capitalismo para continuar con su afán de reproducción, lo que va quedando es la degradación del medio natural, base esencial para la extracción de materias primas que alimentan a las tecnologías de última generación. La pregunta que surge en este contexto es ¿cómo se las arreglará el capitalismo para continuar el ciclo repetitivo de reproducción?

La extensión de la mercancía en la sociedad capitalista consiste precisamente en el esfuerzo permanente por traducir la naturaleza y todos los elementos que la forman, incluido el ser humano, en una más "aunque no lo sea". Las técnicas utilizadas para llevar a cabo este proceso de mercantilización en el mundo son combinados: métodos legales, ilegales, políticos, y hasta "terroristas y militares" (Casanova, 2006: 4). Las guerras en varios países del oriente medio, desde fines de siglo XX y hasta hoy, están matizados con todos estos procedimientos, para ejercer la dominación y el sometimiento de la naturaleza incluidos sus pueblos.

Bartra plantea, también, que Marx "nos legó una visionaria formulación protoecologista" de gran utilidad hoy para comprender la nueva contradicción que se le plantea al 
capitalismo contemporáneo; y lo encuentra en el siguiente argumento:

Todo progreso realizado en la agricultura capitalista, no es solamente un progreso en el arte de esquilmar al obrero, sino también en el arte de esquilmar a la tierra, y cada paso que se da en la intensificación de su fertilidad dentro de un período de tiempo determinado, es a la vez un paso dado en el agotamiento de las fuentes perennes que alimentan su fertilidad [...] la producción capitalista sólo sabe desarrollar la técnica y la combinación del proceso social de producción socavando al mismo tiempo las dos fuentes originarias de toda riqueza: la tierra y el hombre (Marx, 1964: 423, 424; en Bartra, 2008: 123).

Destacamos la importancia que reviste esta tesis clásica de Marx que nos pone en perspectiva la noción conceptual que él tenía no sólo de las fuentes originarias de donde surge la riqueza, sino también de lo que entendemos en este trabajo por naturaleza; es decir, por un lado, la naturaleza humana (expresada por Marx en el obrero que produce) y, por el otro, la naturaleza externa al ser humano (expresada por Marx en la "tierra") fuente de fertilidad natural y vital para la producción alimentaria de la humanidad.

O bien, como lo analiza el científico social húngaro-estadounidense Karl Polanyi, quien siguiendo a Marx, desarrolló a mediados del siglo pasado la anterior contradicción planteada por éste último al decir:

Una economía de mercado debe comprender todos los elementos de la industria, incluidos la mano de obra [y] la tierra [...] Pero la mano de obra y la tierra no son otra cosa que los seres humanos mismos, de los que se compone toda sociedad, y el ambiente natural en que existe tal sociedad. Cuando se incluyen tales elementos en el mecanismo del mercado, se subordina la sustancia de la sociedad misma a las leyes del mercado [...] Pero es obvio que la mano de obra [y] la tierra no son mercancías [...] El trabajo es sólo otro nombre para una actividad humana que va unida a la vida misma, la que [...] no se produce para la venta [...] La tierra es otro nombre de la naturaleza, que no ha sido producida por el hombre [...] Ahora bien [...] si se permitiese que el mercado fuese el único director del destino de los seres humanos y de su entorno natural [...] se demolería la sociedad..., la naturaleza quedaría reducida a sus elementos [...] los paisajes se ensuciarían, los ríos se contaminarían [...] se destruiría el poder de producción de alimentos y materias primas (Polanyi, s.a.: 122-124; en Bartra, 2008: 123).

Como podemos apreciar -y aparte de que la última parte de la cita, ya es el mundo que vivimos hoy-, Polanyi supera toda noción fragmentaria que podamos tener acerca del ser humano y naturaleza, ya que teóricamente analiza ambos conceptos fundidos en una única relación dinámica ("tierra" y "mano de obra") del cual surge una especie de síntesis: el ser humano, que en su devenir histórico construye la sociedad. De ahí su crítica a la sociedad del mercado que pretende hoy más que nunca subordinar esa "sustancia" derivada de la dialéctica: ser humano-naturaleza (o "tierra") y su correlato: el "trabajo", convertido ahora en una mercancía más, como sería un quintal de arroz producido para el mercado o un celular de última generación.

En resumen, la extensión de las mercancías en la sociedad capitalista es asimilable a la tesis del "mercado total" sostenida por Hinkelammert y Mora $(2005: 305,306)$ en la que incluso la naturaleza -y con ella el agua- que no es producida por el trabajo humano ha sido ya incorporada a la lógica mercantilista de la acumulación del capitalismo contemporáneo. En este marco categorial es que cabe analizar el agua en el contexto de economías periféricas como la nuestra.

\section{Los nuevos fetiches de la mercancía}

En el fondo, se trata de la crítica marxista al pensamiento burgués, concretamente al fetichismo de la mercancía. Este fenómeno del capitalismo le da vida o sustancia a las cosas u objetos asignándoles el carácter de sujetos además, las cosas aparentan asumir las relaciones sociales en el proceso de intercambio mercantil. En el caso de los sujetos (la "mano de obra" dirá Polanyi), el obrero o el "trabajo vivo" (Marx), se vuelven objetos como simples mercancías a intercambiarse 
en el mercado de trabajo. Entonces, los objetos dotados de ese poder "mágico" (el fetiche) se vuelve en contra del sujeto que lo ha producido, lo invisibiliza y le borra las "cicatrices" que deja en el obrero, en el trabajador, el proceso de explotación (Kohan, s.f.: 357).

La inversión operada de sujeto a objeto es perversa sin embargo, ha sido posible gracias a la mediación del fetiche que oculta la crudeza de las relaciones sociales producidas en el mundo del trabajo en las que el ser humano aparece "cosificado". Este es el secreto de la mercancía, que siendo una "cosa" devino en "sujeto". Marx en El Capital, Volumen I, p. 89, citado en Holloway, haciendo referencia a los productores lo argumenta en estos términos:

$[L]$ as relaciones sociales entre sus trabajos privados se les ponen de manifiesto como lo que son, vale decir, no como relaciones directamente sociales trabadas entre las personas, sino por el contrario como relaciones propias de cosas entre las personas $y$ relaciones sociales entre las cosas. (Holloway, 2004: 72)

No obstante, para Holloway el mundo de fetiches no es un proceso consumado, sino más bien "un proceso activo de fetichización", lo que significa que para él las relaciones sociales están en una permanente contradicción entre el proceso de "fetichización" de dichas relaciones sociales y las "tendencias antifetichizantes" que se le oponen como un contrario. De acá se deriva que la dominación capitalista es "la lucha por fetichizar" y, en consecuencia, las luchas sociales del sujeto son a su vez la lucha por des-fetichizar las relaciones sociales cosificadas.

Sin embargo, siguiendo la sugerencia de Bartra (2008:143), debemos agregar que la desfetichización de lo fetichizado incluye también el "valor económico" de trabajos y de "bienes y servicios" que surgen al margen de las relaciones directas de explotación de "trabajadores invisibilizados" de los que se beneficia el capital al apropiarse de otros excedentes generados.

A partir de esta noción contemporánea diríamos que el fetiche de la mercancía ha invadido hoy día las relaciones: ser humano-naturaleza cuando se insiste, por ejemplo, en ponerle precio ("valor de cambio") a todos los elementos que la forman y que no han sido producidos por la mano humana mediante el trabajo, es decir, que tienen un "valor de uso" para los individuos. Pensemos por un momento el negocio del agua en Costa Rica, para el año 2012 había 32 marcas de agua operando, una "industria" que reportó ganancias de \$39,4 millones de dólares (Brenes, 2013: 1-2).

De nuevo resuena la tesis "protoecologista" de Marx, citada por Bartra en líneas anteriores, en el tanto la explotación del agua en Costa Rica significa también ese "arte" propio del capitalismo periférico del siglo XXI de esquilmar a la tierra (equivalente de la naturaleza), particularmente de esquilmar el agua a favor de los procesos de mercantilización en marcha.

Bajo la premisa ya comentada, valga enfatizar que el capitalismo se beneficia de las formas no capitalistas de producción; se trata de una idea que "está implícita en un modo de producir que necesita tratar como mercancía a lo que no lo es" (Bartra: 2008: 123). Sería una tesis que calza bien en el caso de nuestro recurso hídrico, esto a partir de que la ideología del mercado fuera arraigándose en las orientaciones políticas de las clases que vienen detentando el poder desde mediados de los años 80 en Costa Rica.

El proceso ha sido un tanto gradual, pero firme; demoliendo poco a poco la institucionalidad reguladora y creando otra muy liviana con orientación desreguladora, cuya síntesis queda expresada en las leyes del Tratado de Libre Comercio (TLC) -ya vigente- y que en muchos de sus principios está incluso por encima de la misma constitución (ver Informe de los Notables sobre roces constitucionales, UCR, 2007). Dicho tratado posibilita, a la clase dominante, acelerar las condiciones para que nuestra naturaleza sea parte del mundo de los grandes negocios es decir, de una mercancía más como cualquier otra aunque, siguiendo a Bartra, realmente "no lo sea". 


\section{El fetiche de la mercancía: \\ notas sobre la teoría del valor}

Partimos de la premisa de que el agua en las actuales condiciones de comercialización se presenta como una mercancía fetichizada; significa que la mercancía, tal como lo plantea Marx, tiene dos connotaciones no siempre tomadas en cuenta por los autores marxistas contemporáneos: una la "dimensión cuantitativa" que se mide por el tiempo de trabajo socialmente necesario que cada una tiene y la "dimensión cualitativa" que conlleva el análisis de la "cosificación, enajenación y reificación de las relaciones sociales" (Kohan: s.f., p.372, 373); a la que, modestamente, le dedicamos el anterior apartado.

En adelante nos referiremos a la "dimensión cuantitativa" del valor inspirados siempre en la teoría que Marx aborda en su obra El Capital, sobre todo en el Volumen I, matizado con algunas interpretaciones contemporáneas de otros autores; esto con el fin de iluminar lo que ocurre con las mercancías para el intercambio y aquellas creadas en "condiciones de producción" atípicas desde el punto de vista del modo de producción capitalista; es decir, cuando las mercancías "no son producidas de acuerdo con las leyes del mercado (ley del valor), pero son tratadas como si fueran mercancías".

\section{- El agua como valor de uso:}

El agua potable como "valor de uso" parte del principio de sobrevivencia y en las sociedades modernas se materializa como medio de consumo colectivo necesariamente canalizada y servida, su característica principal es que está destinado al bien común y, por lo tanto, es un valor que no persigue en sí mismo el lucro y la ganancia, no es su función.

Por el hecho de que en esta dimensión el agua no esté destinada al mercado para generar ganancia surge la interrogante ¿genera o no valor agregado? Consientes de que este es un concepto económico y un tema amplio que amerita ser profundizado, la explicación que encontramos y puede darse en lo inmediato es que si el recurso hídrico para la sobrevivencia -uso y consumo humano- es extraído de sus fuentes naturales, no adquiere valor agregado toda vez que su apropiación es directa.

Ahora bien, aunque orientado a la sobrevivencia, cuando ese recurso natural asume el carácter de medio de consumo colectivo, justamente por el hecho de suplir necesidades vitales que no están al alcance de los consumidores finales, el agua experimenta un recorrido que inicia en su fuente natural, pasa por la distribución y finaliza con el consumo masivo del cual emerge un "valor agregado". Esto quiere decir, que el recorrido implica necesariamente inversiones en fuerza de trabajo y tecnología que a la vez conllevan una serie de costos, como por ejemplo de purificación o desinfección, avenamiento, distribución, administrativos, entre otros.

Es comprensible que al finalizar cada recorrido de la incesante provisión el líquido llega provisto de un "valor agregado" que le pone un precio al agua como servicio y no como mercancía y que ineludiblemente el consumidor tiene que pagar.

El significado del proceso se puede resumir diciendo que este expresa el valor de uso del agua y es una operación de servicio colectivo que genera valor agregado en atención a la inversión y los costos subsumidos en el recorrido que tiene lugar entre la captación del recurso hídrico de su fuente natural, su distribución social y el consumo masivo. ¿Finalidad de la cursiva y el subrayado? Subrayado busca resaltar

En otras palabras, aunque como valor de uso el agua adquiere un "valor agregado" expresado en el trabajo humano que implica mantener en funcionamiento los sistemas de acueductos, esta no llega a incorporar un valor de mercado. Para ello, es de vital importancia la mediación de un Estado que regule la administración de los recursos naturales (en nuestro caso: del agua); una regulación que, para Bartra (2008:129), siempre está condicionada por la presión de "fuerzas sociales" que son "distintas del capital".

Precisamente aquí está la tensión a la que nos enfrentamos hoy entre las fuerzas del capital que 
ven en el agua otra mercancía contra las fuerzas sociales y comunales que luchan por preservar el recurso hídrico como un valor de uso.

- El agua como valor de cambio:

En relación con esta otra noción del valor Marx sostiene que:

[N]uestro capitalista persigue dos objetivos. En primer lugar, producir un valor de uso que tenga un valor de cambio, producir un artículo destinado a la venta, una mercancía. En segundo lugar, producir una mercancía cuyo valor cubra y rebase la suma de valores de las mercancías invertidas en su producción, es decir de los medios de producción y de la fuerza de trabajo, por los que adelantó [...] dinero en el mercado de mercancías. No le basta producir un valor de uso; no, él quiere producir una mercancía [...] un valor; y tampoco se contenta con un valor puro y simple, sino que aspira a una plusvalía, a un valor mayor. (Marx, 1986: 148)

Esta es la lógica o racionalidad medio-fin que recorren los "capitales individuales" que ahora invierten en recursos naturales, particularmente de los que se orientan al recurso hídrico en Costa Rica. Esto significa que su interés no es solamente producir un valor de uso sino que, además, tenga la "virtud" de desdoblarse en mercancía.

El agua, en términos de "valor de cambio", se basa en los principios de lucro y ganancia propios de la producción capitalista, los cuales son elementos fundamentales de propósito que permiten diferenciar esta dimensión de valor respecto a la anterior.

Encontramos que comprender la otra dimensión del valor atinente al bien material denominado "agua" tiene un grado mucho mayor de dificultad y complejidad al menos por dos razones que se deducen de los procesos productivos:

1. En tanto recurso natural como bien material, el agua actúa en la fase productiva y de circulación, ya que es utilizada unas veces solo en su esencia en términos de materia prima (ej.: bebidas gaseosas); en ocasiones se muestra con su misma apariencia y esencia como factor productivo en sí mismo (agua pura embasada) y en otras también como insumo, esconde su apariencia y esencia detrás de otra mercancía (ej.: el agua de que mueve una caldera o sirve de base para la producción de "chips").

En resumen, el agua en su condición de elemento productivo actúa en el proceso de producción y el de circulación de mercancías de forma variada y cumpliendo en cada caso una función específica.

a. Al ser una producción en masa, consustancial al sistema capitalista, ciertamente el producto está destinado a un consumo masivo, lo cual crea la apariencia de que las empresas (industriales o comercializadoras) están interesadas en "el bien común";

b. Por ende, la clave para entender la lógica de este proceso productivo en el que interviene el recurso hídrico, está en la forma de apropiación del bien que produce (privada) y no en las necesidades que resuelve.

Pero, ¿qué necesidades resuelve el agua en su condición mercantil? Desde esta perspectiva o dimensión de valor se puede afirmar que "suple" y "crea" necesidades. En el primer caso, cubre necesidades de sobrevivencia o salud mediante la comercialización del agua pura embasada, así como, necesidades que podrían denominarse superfluas y convencionales que se suplen mediante la producción y comercialización, por ejemplo, de bebidas saborizadas o combinadas con productos naturales que son de uso y acceso común y socialmente demandadas.

El significado de este proceso puede resumirse diciendo que este expresa el valor de cambio del agua y es una operación productiva cuyo valor agregado es consustancial y característico de los procesos de industrialización, en tanto transforma la materia prima (agua) en una mercancía que circula como cualquier otra, sea preservando su forma natural ocirculando en forma aparencial. 
Aquí, el "valor agregado" se da típicamente en virtud de las inversiones de capital en tecnología y fuerza de trabajo a la que se agrega un "plusvalor"; todo ello subsumido en el recorrido que tiene lugar, entre el punto de partida o fuente natural de la captación del recurso hídrico, su transformación en mercancía, su distribución y consumo selectivo de quienes pueden pagar el producto al precio que impone el mercado.

\section{- Agua, valor y conflicto}

Bartra sugiere que en el proceso de "explotación de la naturaleza", al igual que en la explotación del obrero, está contenida la resistencia y la lucha social, ya que "la apropiación de la naturaleza es obra de capitales individuales a los que mueve la competencia" y trata de disminuir costos transfiriéndolos "a quién se deje" (grupos sociales como campesinos, indígenas) y "endosándolos" a los que vienen después, aunque por este mecanismo, se rebase la capacidad de carga de los ecosistemas, "contaminación del medio y agotamiento de los recursos renovables". Pero la explotación de la naturaleza y su potencialidad conflictiva, opera desde distintos flancos, al respecto (Bartra, 2008: 129) nos dice:

La apropiación tecnológica y económica de la naturaleza por el capital no se opera sólo por mediación de los pequeños y medianos agricultores. En realidad predominan la privatización y apropiación material de los recursos naturales (lo que incluye tierras, aguas y minerales pero también biodiversidad, territorio, paisaje, clima, etcétera), practicadas directamente por el gran dinero. Dicho apoderamiento es tan "ciego y desmedido como el que se ejercía sobre los obreros y campesinos si los trabajadores no le pusieran un hasta aquí".

Buscando asociar las nociones de valor con el significado de la participación social en torno al agua planteamos la hipótesis de que los procesos que subyacen a las dos dimensiones de valor analizadas son potencialmente conflictivos.Sobre todo porque si lo analizamos a la luz del planteamiento anterior, en efecto, la explotación del agua (la naturaleza) está mediada por procesos de apropiación tecnológica y económica que opera a nivel global; para ello es fundamental el papel de las transnacionales en el área del agua, medicinas, agroquímicos, bebidas gaseosas, entre otras, quienes están privatizando los recursos naturales y una vía legal y sutil de esta apropiación son los tratados comerciales que se firman en todas partes.

Volviendo a la noción de valor de uso (medio de consumo colectivo), es menester decir que en la orientación de este valor se distingue una forma de "apropiación social" en donde el conflicto se estaría derivando de la inequitativa distribución del recurso.En lo que respecta a la noción de "valor de cambio", se advierte una forma de "apropiación privada" que es contradictoria con la anterior y el conflicto pareciera aflorar cuando esta apropiación es excesiva y en detrimento de la primera. Ambas situaciones son empíricamente observables en nuestro medio.

De modo que, como se indicara en párrafos anteriores, la relación humana con el agua puede conflictuarse en grados y formas distintas; así, el conflicto puede ser latente y visible pero no trasciende (abusos o restricciones en el acceso al agua que no se denuncian) o puede ser visible pero con trascendencia (cuando el abuso se denuncia o se enfrenta y sale a la luz pública) o no visible (cuando el problema se esconde o se maquilla).

En otras palabras, aunque no es perceptible a simple vista, cuando se manifiesta un conflicto por el agua tiene detrás la tensión que conlleva el agua como valor y el conflicto no es más que el debilitamiento o ruptura de uno de los puntos críticos de esa tensión, la cual, como hemos visto, siempre está mediada por un sujeto social que se opone a la mercantilización de lo que para este seguirá siendo valores de uso para la vida.

\section{Fetichización discursiva desde el poder}

Podríamos decir, entonces, que asistimos a una transición cultural-discursiva con respecto al tema del agua, la cual caracterizamos como un tipo de discurso "fetichizado" desde el poder es decir, que hace ver como intrascendente ("cosificado" diría Marx), lo que es fundamental o 
sustantivo (el "sujeto" en Marx)) y a la inversa, sustancializa (lo convierte en "esencia"), lo cual es meramente formal y accesorio (el objeto, la "cosa"). La teoría crítica del fetichismo se basa en esta crítica.

En esta línea, el discurso cultural-ambiental y "proteccionista" de "paz con la naturaleza", que se promueve en el país desde hace algún tiempo, está "fetichizado" desde las mismas instancias que gobiernan el poder del Estado en donde se mezclan muchos intereses del capital privado nacional y extranjero. El mejor ejemplo en Costa Rica ocurrió hace pocos años con el polémico proyecto de la minería a cielo abierto por parte de una empresa transnacional canadiense, el cual fue tristemente declarado como de "interés nacional" por una persona del mundo político y empresarial costarricense de gran prestigio, tanto nacional como internacionalmente.

Aunque en este caso particular, la ciudadanía, sobre todo aquella representada por organizaciones ambientalistas, estudiantes universitarios y de secundaria, comunidades del norte contra la minería, entre otros actores sociales, fueron verdaderos "sujetos de la acción" histórica que se encargaron de "desfetichizar" el discurso alienante de todas las instancias jerárquicas del poder e instituciones del Estado y demás fuerzas económicas que confabulaban para que este "ecocidio" a la naturaleza tuviera toda la viabilidad política y jurídica.

Sin embargo, hay otros fetiches por ser develados. Uno de ellos recorre y se encarna en una naturaleza cada vez más enajenada de su relación con lo humano, que nubla y fragmenta la mirada crítica, que la hace ver como algo externo a ser dominado, expoliado y sin consideraciones éticas de respeto y equilibrio (sociedad-naturaleza) de ninguna clase.

Es un discurso "fetichista" que considera al agua -sea por "moda" cultural, por necesidad o por razones de acumulación- como elemento que se ha posicionado en espacio natural para hacer negocios lucrativos por lo que nos hace ver como "natural" que el agua sea una mercancía más. Atrás quedaron para estos grupos empresariales, y sobre todo para jerarcas estatales vinculados con el tema ambiental, los debates sobre el acceso al agua como un derecho, ahora elevado al rango de derechos humanos para todas las personas, por parte de la Asamblea General de las Naciones Unidas a partir del año 2012.

Derrotar los fetiches construidos alrededor del agua como mercancía por el discurso dominante es una tarea urgente para preservar este recurso como un valor de uso permanente y accesible para todas las personas, sin menoscabo de las restantes formas de vida natural del planeta, por lo que el desafío no es solamente social, sino además el de un imperativo de ética ecológica ante las otras naturalezas que no pueden defenderse solas.

\section{Referencias}

Arias Valverde, Oscar (2004). La estructura jurídica progresiva de la seguridad social. En: La construcción de la seguridad social (Miranda Gutiérrez Guido y Zamora Zamora, Carlos -editores-). EUNED, S.J.

Bartra, Armando (2008). El hombre de hierro: los límites sociales y naturales del capital. Universidad Autónoma de la ciudad de México, $1^{\text {a }}$ edic., editorial Itaca, D.F.

Baraona, Miguel (2007). Ecos cercanos: los clásicos y la cuestión étnica. LOM ediciones, Santiago.

Barillas, Byron y Bonilla, Luis (2012). Acueductos rurales y participación social: el carácter social y polifacético del agua en los cambiantes contextos políticos en Costa Rica. (Informe de investigación -inédito-). UNED, Vicerrectoría de Investigación, E.C.S.H., cátedra de sociología.

Beinstein, Jorge (2009). El comienzo de un largo viaje: crepúsculo del capitalismo, nostalgias, herencias, barbaries y esperanzas a comienzos del siglo XXI. En: http://www. rebelion.org, recuperado el 6 de julio del 2013.

Brenes Q., Cesar Augusto. 32 marcas de agua embotellada inundan los supermercados de Costa Rica. En: http//www. elfinancierocr.com, recuperado el 8 de abril del 2013.

Camacho, Daniel (2001). Fundamentos de sociología. $8^{\mathrm{a}}$ reimpresión, EUNED, S.J.

González Casanova, Pablo (2006). ¿Por qué estamos aquí? En: http://www.inep.org/content/view.Portal INEP, recuperado el 10 de mayo del 201. 
Holloway, John (comp). Clase = lucha: antagonismo social y marxismo crítico. $1^{\text {a }}$ ed. Ediciones herramienta, Buenos Aires.

Hinkelammert, Franz J. (s.f.). El huracán de la globalización: la exclusión y la destrucción del medio ambiente vistos desde la teoría de la dependencia. En Antología del curso: El proceso de globalización, pobreza y desarrollo en América Latina. Doctorado en estudios latinoamericanos, Facultad de Filosofía y Letras, Universidad Nacional Autónoma, Heredia, 2007.

Hinkelammert, Franz. j. y Mora J., Henry (2005). Hacia una economía para la vida. $1^{\mathrm{a}}$ ed., DEI, San José.

Kohan, Néstor (s.f.). Nuestro Marx. En: http://lahaine.org/ amauta, recuperado el 15 junio del 2012.

Marx, Karl (1986). El Capital: crítica de la economía politica, Tomo I. Editorial de Ciencias Sociales de la Habana, la Habana.

Marx, Karl (1989). Contribución a la crítica de la economía política. Editorial progreso, Moscú.
Mora Agüero, Jorge Cayetano (1992). Las juntas progresistas. Organización comunal autónoma costarricense -19211980. EDITORIALPEC 91, Heredia.

Sunkel, Osvaldo y Paz, Pedro (1978). El subdesarrollo latinoamericano y la teoría del desarrollo. Décimoprimera edición, siglo XXI editores, D.F.

Shiva, Vandana (s.f.). Las guerras del agua: privatización, contaminación y lucro. Siglo XXI editores. En http://www. google.com, recuperado 10 de junio del 2013.

Urrea, D. y Pinzón, M. (2013, 6 de junio). El agua y el derecho ¿humano demasiado humano? En: http://www.rebelion. org, recuperado el 20 de junio del 2013.

Vargas Solís, Luis Paulino (2013, 30 de junio). La economía de Costa Rica en 2013: el frenazo. En: http://sonarconlospiesenlatierra.blogspot.com/2013/06/la-economiade-costa-rica-en-2013-el-html, recuperado el 3 de julio del 2013.

Vargas Solís, Luis Paulino (2008). El verdadero rostro de la globalización: Vol. I: la globalización sin alternativa. EUNED, S.J. 
- 